Int. J. Dev. Biol. 50: 491-497 (2006)

doi: $10.1387 / \mathrm{ijdb} .052117 \mathrm{em}$

Original Article

\title{
Molar tooth development in caspase-3 deficient mice
}

\author{
EVA MATALOVA*,1, PAUL T. SHARPE ${ }^{3}$, SAOUIB A. LAKHANI ${ }^{4}, \mathrm{KEVIN} \mathrm{A.} \mathrm{ROTH}^{5}, \mathrm{RICHARD} \mathrm{A.} \mathrm{FLAVELL}^{4}$, \\ JANA SETKOVA ${ }^{1}$, IVAN MISEK ${ }^{1}$ and ABIGAIL S. TUCKER ${ }^{2}$ \\ ${ }^{1}$ Laboratory of Animal Embryology, Institute of Animal Physiology and Genetics, Academy of Sciences, Brno, Czech Republic, \\ ${ }^{2}$ Department of Craniofacial Development and Orthodontics, King's College, Guy's Hospital, London, U.K., ${ }^{3}$ Department of Craniofacial \\ Development, King's College, Guy's Hospital, London, U.K., ${ }^{4}$ Howard Hughes Medical Institute, Yale University School of Medicine, New \\ Haven, Connecticut, USA and ${ }^{5}$ Department of Neuropathology, University of Alabama at Birmingham, USA
}

\begin{abstract}
Tooth morphogenesis is accompanied by apoptotic events which show restricted temporospatial patterns suggesting multiple roles in odontogenesis. Dental apoptosis seems to be caspase dependent and caspase-3 has been shown to be activated during dental apoptosis. Caspase-3 mutant mice on different genetic backgrounds were used to investigate alterations in dental apoptosis and molar tooth morphogenesis. Mouse embryos at E15.5 were analyzed to reveal any changes in enamel knots, which are transient structures eliminated by apoptosis. In caspase- $3^{-/-}$mice on the B57BL/6 background, disorganization of the epithelium was found in the original primary enamel knot area and confirmed by altered expression of Shh. Despite this early defect in molar tooth development, these mutants showed correct formation of secondary enamel knots as indicated by Fgf-4 expression. Analyses of adult molar teeth did not reveal any major alterations in tooth shape, enamel structure or pattern when compared to heterozygote littermates. In caspase- $3^{-/-}$mice on the $129 \times 1 /$ SvJ background, no defects in tooth development were found except the position of the upper molars which developed more posteriorly in the oral cavity. This is likely, however, to be a secondary defect caused by a physical squashing of the face by the malformed brain. The results suggest that although caspase- 3 becomes activated and may be essential for dental apoptosis, it does not seem fundamental for formation of normal mineralised molar teeth.
\end{abstract}

KEY WORDS: tooth development, dental apoptosis, caspase-3 mutant

\section{Introduction}

Apoptosis is an essential process in embryogenesis as well as adult cell, tissue and organ maintenance. Research efforts over the last years have led to the identification of many genes and interactions between their protein products that control the initiation, execution and regulation of programmed cell death via apoptosis.

During tooth development apoptosis occurs at all stages, particularly in early morphogenesis but also in dentinogenesis, amelogenesis and during tooth eruption (reviewed in Matalova et al., 2004). Dental apoptosis has been suggested to play both passive and active roles in tooth bud formation and morphogenesis, in the reduction of the dental lamina and in the elimination of enamel knots - signalling centres at the heart of developing teeth. The location of apoptotic cells during tooth development has been described, however, there is little functional evidence concerning mechanisms and roles of dental apoptosis.
Apoptosis is mediated by distinct pathways, initiated from outside the cell (extrinsic or death receptor pathway) or from inside the cell (intrinsic or mitochondrial pathway). In both cases, signalling results in the activation of a family of cystein proteases, named caspases that act in a proteolytic cascade (Earnshaw et al., 1999; Shi et al., 2002). Caspases are required for most types of apoptosis (Nicholson and Thornberry, 1997), however, they can also play roles in non-apoptotic pathways (Gulyaeva, 2003; Schwerk and Schulze-Osthoff, 2003; Kumar, 2004). The proapoptotic caspases have been shown to be required for embryonic development and their deficiency tends to cause perinathal letality (Zheng et al., 1999).

Overexpression of different caspases by transfection into cells can induce apoptosis in certain cell lines (Wang and Lenardo, 2000), however, it is not clear if apoptosis induced in this way

Abbreviations used in this paper: FGF, fibroblast growth factor; PCNA, proliferating cell nuclear antigen; Shh, sonic hedgehog.

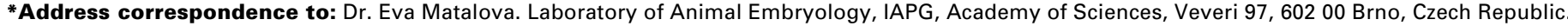
Fax: +4-205-4921-1482. e-mail: matalova@iach.cz
} 
represents the roles of caspases in vivo. Deletion of individual caspases is therefore necessary for understanding their physiological functions (Ranger et al., 2001). Targeted disruption of caspase genes in mice has revealed different requirements for individual caspases during mammalian development (Zheng et al., 1999). Specifically, caspase-8 -/- embryos die around E11 days with impaired heart development (Varfolomeev et al., 1998), whereas caspase-9 -/- mice die before or shortly after birth and exhibit severe brain abnormalities (Kuida et al., 1998). Caspase3 -/- mice are usually perinatally lethal (Kuida et al., 1996). The absolute requirement of the caspase-9/caspase-3 pathway for neuronal cell death and caspase- 8 for the proper formation of heart muscle suggests a strict tissue-specific requirement for certain caspases during development.

In caspase-3 knock-out mice, apoptosis is rapidly reduced in dividing neuroepithelial cells in the central nervous system. These mice are born at a low frequency and usually die perinatally or a few weeks after birth and show structural disorganisation and partial resistance of $\mathrm{T}$ lymphocytes to activation-induced cell death (Kuida etal., 1996). Although the most significant apoptosis deficiency in caspase-3 knock-out mice is displayed in the central nervous system, apoptosis-associated alterations are also absent or delayed in other cells (Zheng et al., 1998).

Activated caspase- 3 was found in the interdigital segments of limbs, in the thymus, small intestine epithelium, kidney and neurons, all areas where cell death occurs naturally during development (Raff et al., 1993; Krajewska et al., 1997; Urase et
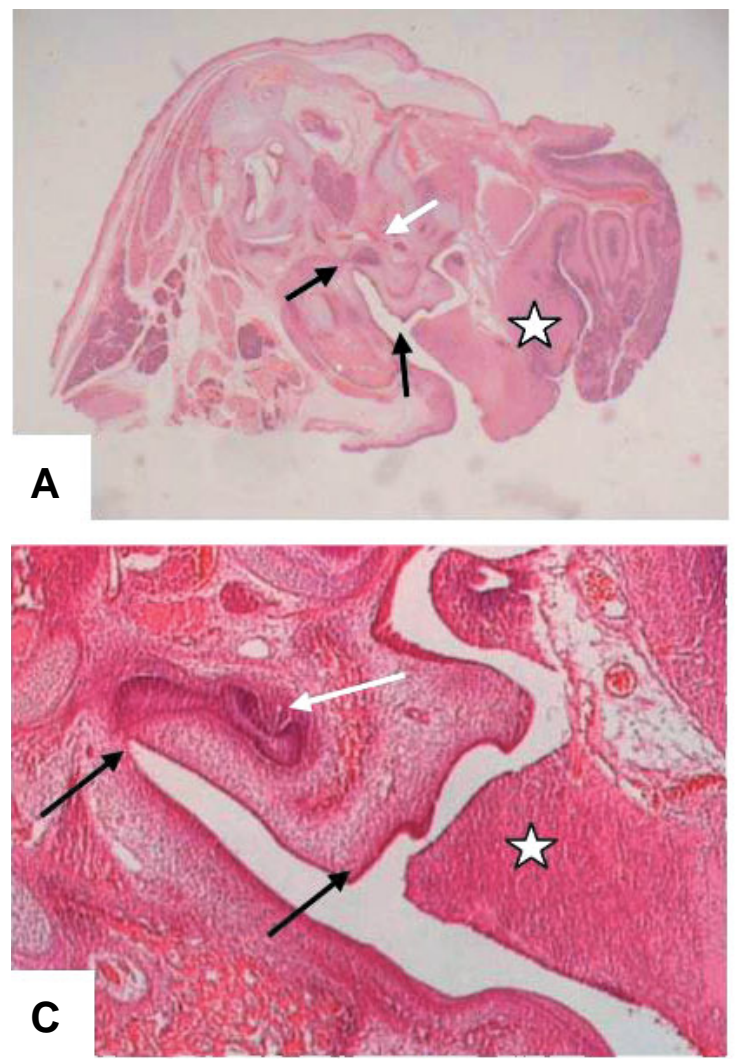

al., 1998; Eijnde et al., 1999; Araki et al., 2003; Resendes et al., 2004). In tooth development, caspase-3 activation was found to correlate with TUNEL-positive cells (Shigemura et al., 2001; Matalova etal., 2005b). In order to investigate the role of caspase3 in tooth development, molar tooth morphogenesis was analyzed in caspase-3 mutant mice on different genetic backgrounds.

\section{Results}

\section{Morphology of the tooth germ}

Caspase-3 deficient mice were investigated on three different backgrounds (B57BL/6, 129X1/SvJ and mixed) at embryonic day (E) 15.5. At this stage the primary enamel knot cells have should disappear by apoptosis and the secondary enamel knots have started to form.

No apparent differences in morphology of the first molar tooth germs, location of the primary enamel knots or distribution of apoptotic cells were observed in wildtype mice from the two background strains, B57BL/6 or $129 \times 1 / S v J$. In all mutant mice, first molar tooth germs reached the early bell stage at the same time as in the corresponding wild types. However, the shape of the bell, particularly the area corresponding to the original primary enamel knot differed in some mutants. Caspase-3 -/- / $129 \times 1 / S v J$ first molar tooth germs did not show any obvious differences compared to caspase-3+/+/129X1/SvJ in frontal sections. In sagittal sections, however, the location of the first molar tooth germs was abnormal, these teeth being found
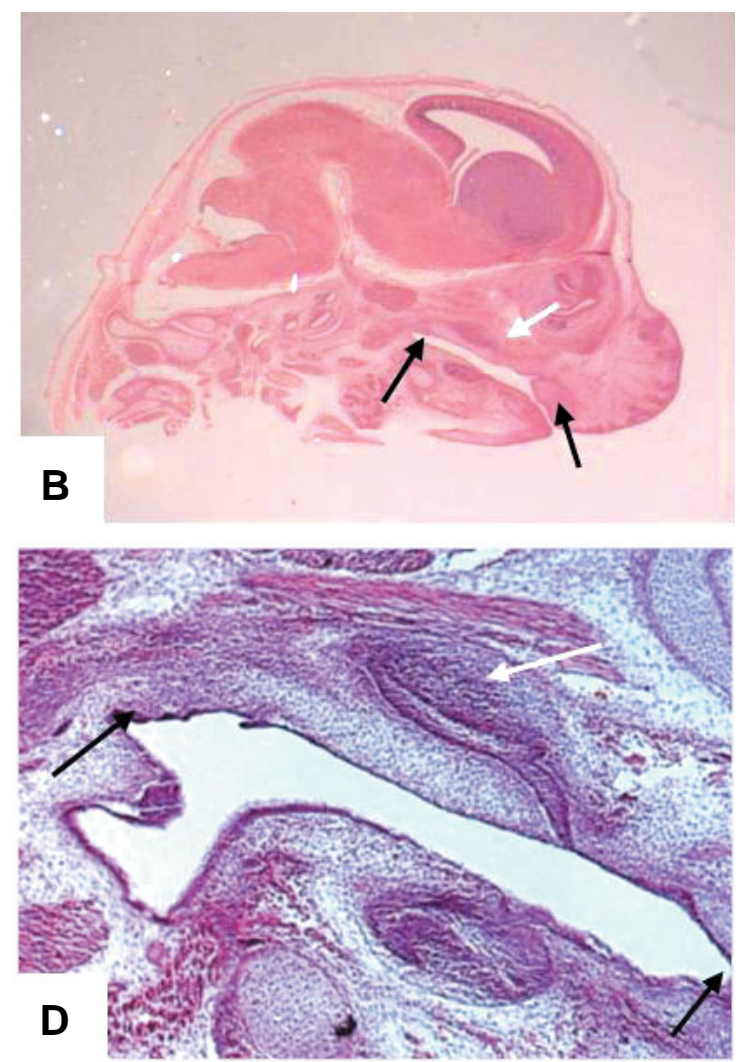

Fig. 1. Position of the first molar tooth germ in the upper jaws of the caspase-3 knock-out mice on the 129X1/SvJ background and the corresponding wild type. Saggital sections, E15.5, haematoxylin-eosin staining. General head morphology: (A) mutant caspase-3 homozygote, (B) wild type. Detailed images of the upper jaw in the caspase-3 knock-out mouse, 129X1/Sv J background (C) and in the wild type (D). Black arrows point to the boundaries of the upper jaw, white arrow points to the first upper molar tooth germ, asterix indicates malformed brain tissue. 
shifted posteriorly in the upper jaw. The mutants on this background have extremely abnormal head morphology and brain malformations (Fig. 1). In contrast, in the caspase-3 -/- on the B57BL/6 background, altered morphology of the first molar tooth germs was found in both upper and lower jaws. In particular, the concave region where the primary enamel knot would have originated appeared to be very disorganized (Fig. 2).

\section{In situ hybridisation}

Due to the most severe defect in tooth morphology being on the B57BL/6 background, these mice were investigated further using in situ hybridisation to identify changes in enamel knot location and secondary enamel knot formation. Location of Shh mRNA in homozygous mutants (Fig. $3 \mathrm{D}, \mathrm{E}$ ) was found to be expanded into the inner dental epithelium compared to heterozygotes (Fig. $3 \mathrm{I}, \mathrm{J}$ ) and the wild type (Fig. $3 \mathrm{~N}, \mathrm{O})$. Fgf-4 expression was found to be nor-
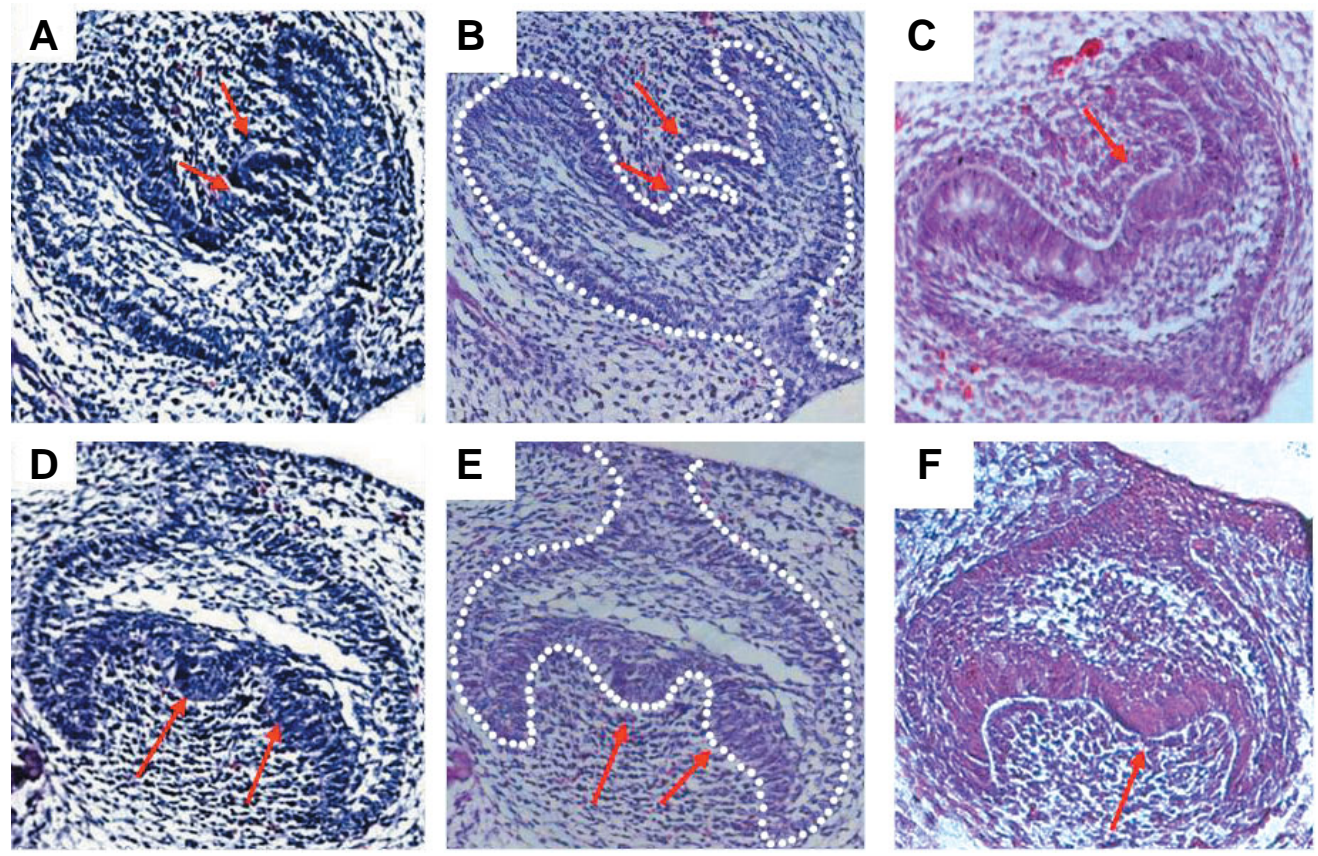

Fig. 2. Morphology of the first molar tooth germs in the caspase-3 knock-out mice on the B57BL/6 background and the corresponding wild type. Frontal sections, E15.5, heamatoxylin-eosin staining. (A, B) Mutant first upper molar tooth germ, (C) wild type first upper molar tooth germ, (D, E) mutant first lower molar tooth germ, (F) wild type first lower molar tooth germ. Red arrows point to regions of disorganized dental epithelium in the mutant $(A, B, D, E)$ corresponding to the original area of the primary enamel knot in the wild type (C,F).

mal in forming secondary enamel knots in both, mutant and the wild type (Fig. 3 B, C, G, H, L, M). However, due to the altered shape of the tooth germ, the position of Fgf-4 expression differed. In the wild type and heterozygotes, Fgf-4 was expressed in two patches located in the concave part of the epithelium facing the mesenchyme, whereas, in the mutants Fgf-4 expression was seen on the convex region of the epithelium in the disorganized central area.

\section{Proliferation and apoptosis}

PCNA was used as a marker to localise the proliferating cells in the mutant tooth germs on the B57BL/6 background at the early bell stage. In both, wildtype and mutant, PCNA positive cells were found in the growing cervical loop and around the primary enamel knot area as previously described (Lesot et al., 1996). The mitotic regions in the mutant were thus unaltered by loss of caspase-3.

Apoptosis was evaluated using morphological criteria based on detection of apoptotic bodies and TUNEL labelling of DNA breaks. No apoptotic bodies were found in the mutant tooth germs at E15.5 and moreover TUNEL labelling showed negative or very weak staining. Weak TUNEL staining has also been reported in other regions of the embryo in the caspase-3 knockout mouse (Woo et al., 1998).

\section{Adult tooth phenotype}

To investigate the adult molar tooth phenotype, lower and upper jaws of the wild type and caspase- $3-/-$ mice on the B57BL/6 background were skinned and skeletons prepared. As shown in Fig. 4, in both, mutants and controls, all three molar teeth developed and did not show any obvious difference in cusp morphology. In order to reveal any internal morphological alterations in the adult molars and to check enamel formation, further histological analysis was performed. Decalcified sagittal jaw sections stained with trichrome did not show any difference in the structure of the molar teeth (Fig. $4 \mathrm{E}, \mathrm{F}$ ). To identify any possible subtle defects in structure of the enamel, upper first molars were prepared for scanning electron microscopy. No obvious defects in enamel formation were found (Fig. $4 \mathrm{G}, \mathrm{H}, \mathrm{I}$, J).

\section{Discussion}

One explanation for how multiple caspases function in vivo proposes that individual caspases act in a tissue specific fashion. However, the simultaneous expression of multiple caspases in most cell types would appear to rule out any simplistic tissue-specific model (Zheng et al.,1999). Nevertheless, several caspase knockout mice do exhibit tissue-restricted phenotypes.

The severity of developmental abnormalities in caspase-3 mutants are known to differ on different genetic backgrounds (Leonard et al., 2002; Urase et al., 2003). Thus, we investigated mutant phenotypes on backgrounds: B57BL/6 and 129X1/SvJ. Surprisingly, the molar tooth morphogenesis was affected particularly in caspase- 3 mutants on the B57BL/6 background. Based on reports of other developmental abnormalities, the caspase-3 knock-out on the B57BL/6 background was expected to have the mildest alteration in molar tooth development and the 129X1/SvJ background the most severe (Urase et 

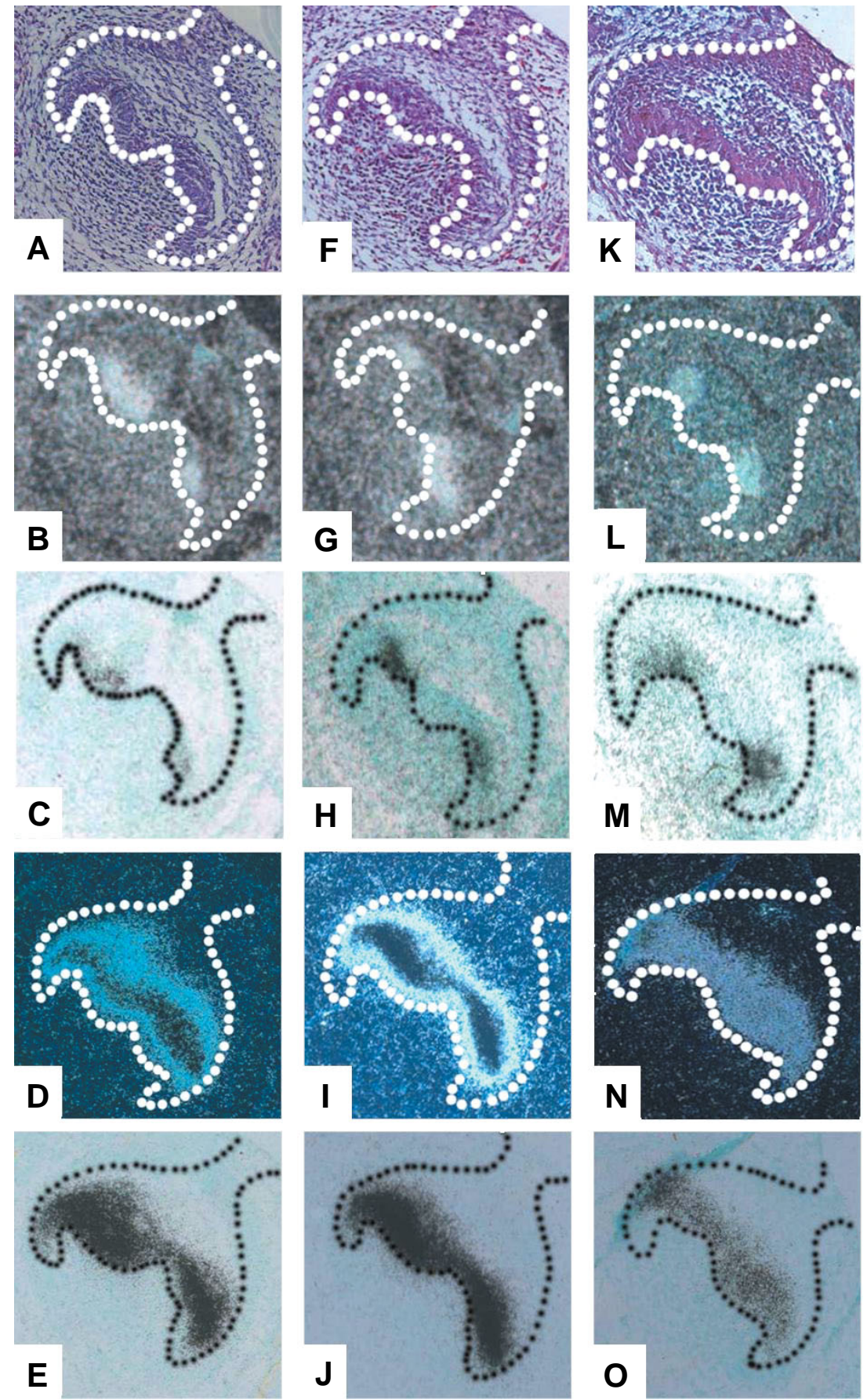

Fig. 3. Evaluation of enamel knot formation in caspase-3 mutants. In situ hybridisation of enamel knot marker mRNA - Shh and Fgf-4 in caspase-3 knock-out homozygote, caspase-3 knock-out heterozygote and wild type mice at E15.5. Frontal sections of first lower molar. (A,F,K) Haematoxylin-eosin staining shows early bell stage of the first lower molar development in the caspase-3 homozygote (A), caspase-3 heterozygote $(F)$ and the wild type (K). (B,G,L) Dark field images, Fgf-4 in situ hybridization, first lower molar, E15.5 of the caspase-3 homozygote (B), caspase-3 heterozygote (G) and the wild type (L). $(\mathbf{C}, \mathbf{H}, \mathbf{M})$ Bright field images, Fgf-4 in situ hybridization, first lower molar, E15.5 of the caspase-3 homozygote (C), caspase-3 heterozygote (H) and the wild type (M). (D,I,N) Dark field images, Shh in situ hybridization, first lower molar, E15.5 of the caspase-3 homozygote (D), caspase-3 heterozygote (I) and the wild type (N). White areas show Shh expression in the dental epithelium. (E,J,O) Bright field images, Shh in situ hybridization, first lower molar, E15.5 of the caspase-3 homozygote (E), caspase-3 heterozygote (J) and the wild type (O). Black areas show Shh expression in the dental epithelium. al., 2003). This observation suggests that different modifier genes are acting on different tissues in the absence of caspase-3 (Zheng et al., 1999).

The enamel knot in mouse molars has been described as a transitory structure with a specific arrangement of cells and accumulation of apoptotic activity (Lesot et al., 1996). In the mouse, specific expression of several signalling molecules such as Shh, BMP-2, 4, 7, Fgf-4 is found in the cells of the primary enamel knot (Jernvall et al., 1998; Vaahtokari et al., 1996) and therefore the enamel knots have been described to act as signalling centres for tooth morphogenesis. The primary enamel knot can be detected from the bud to early bell stage and becomes eliminated by apoptosis at the bell stage. We thus concentrated on this stage of molar tooth development in order to reveal any relationship between caspase-3 deficiency and tooth morphology, dental apoptosis, proliferation, secondary enamel knot formation as well as final adult molar tooth shape and structure.

The absence of caspase- 3 on the B57BL/6 background led to an altered morphology of the developing tooth germ at the early bell stage, when the primary enamel knot disappears and the tooth germ progresses to the next developmental stage. These alterations can be explained by the prolonged survival of primary enamel knot cells and the normal proliferation of surrounding tissue around this cluster. The primary enamel knot has been shown to persist after addition of a general caspase inhibitor in culture (Coin et al., 2000).

Expression of Shhand Fgf4, markers of primary enamel knot cells, differed only slightly in the mutant compared to the wild type. In our study the only difference observed was a spread of Shh into the inner dental epithelium. This may be due to the longer survival of some of the original primary enamel knot cells, which then may expand in the growing inner dental epithelium. This hypothesis could be supported by the findings of Coin et al. (2000) who demonstrated a persistent enamel knot after general caspase inhibition in vitro and moreover, weak expression of Shh in this cell population. However, at least in the mutant it appears that these cells later become scavenged, perhaps due to early phosphatidylserine translocation and thus the cells destined to die may be already tagged before caspase-3 activation (Verhoven et al., 1999). Absence of caspase- 3 could thus simply delay their loss from the tissue. This fact could explain the normal adult tooth phenotype in the mutants where it appears any abnormal early development is rescued.

Another possible explanation for the lack of a tooth phenotype could be compensatory activation 
of other executive caspases, such as caspase- 6 or caspase-7 since these have a relatively high sequence homology. Such compensation has been described in vitro (Zheng et al., 2000). Multiple caspases and regulators of caspase activation may have evolved to provide mammals with greater plasticity to respond to more diverse stimuli, explaining why knock-outs of only one caspase do not lead to complete developmental arrest (Zheng et al., 1999; Zakeri et al., 2005). Compensatory caspase activation could thus bypass the requirement for caspase- 3 in tooth development. In knock-out mice, other effector caspases than caspase3 seem to act downstream of apical caspases. This is observed in the caspase- 9 homozygotes where the phenotype is similar but more severe than in caspase3 mutants (Hakem et al., 1998; Kuida et al., 1998). Thus, caspase-3 may not be necessary for a successful elimination of primary enamel knot cells after termination of their function. The arrest in apoptotic cell death observed in the primary enamel knot, however, seems to lead to short-term morphological alterations of the developing molar tooth germs that nevertheless can recover during further embryonic tooth development. Although the primary enamel knots are disorganised, the secondary enamel knots appear in the correct place at the correct time. These findings support our previous hypothesis (Matalova etal., 2005a) that there is no cellular continuity between primary and secondary enamel knots. Thus a defect in the morphology of the primary enamel knot area does not necessarily lead to a defect in the origin of secondary enamel knots.

Apoptosis can be detected at different stages of enamel development: in differentiated ameloblasts, in transitional ameloblasts and in maturing ameloblasts (Bronckers et al., 2000). We therefore investigated the possible impact of caspase-3 deficiency on final enamel formation in adult molar teeth. Scanning electron microscopy did not reveal any changes in enamel formation or ameloblast density, suggesting engagement of compensatory pathways or non-caspase-mediated cell death in the reduction of ameloblast numbers.

In vivo, lack of caspase-3 has been suggested to result in increased proliferation and decreased differentiation due to the decreased activation of caspase-3 substrates (such as PKC-delta) which function as positive regulators of differentiation (Ryoo et al., 2004). Such compensatory proliferation of the surrounding tissue was not confirmed in our analysis of the tooth germs of mutant mice using PCNA to detect proliferating areas in the dental epithelium and mesenchyme.

In the 129X1/SvJ caspase-3 deficient mice, a posterior shift in the first upper molar formation was revealed. This may be explained as a secondary defect caused by the prominent brain malformations. In these mice the brain is hugely expanded and protrudes frontally over the developing face. This appears to physically restrict facial development and prevent fusion of the maxilla and the nasal processes of the upper jaw. In
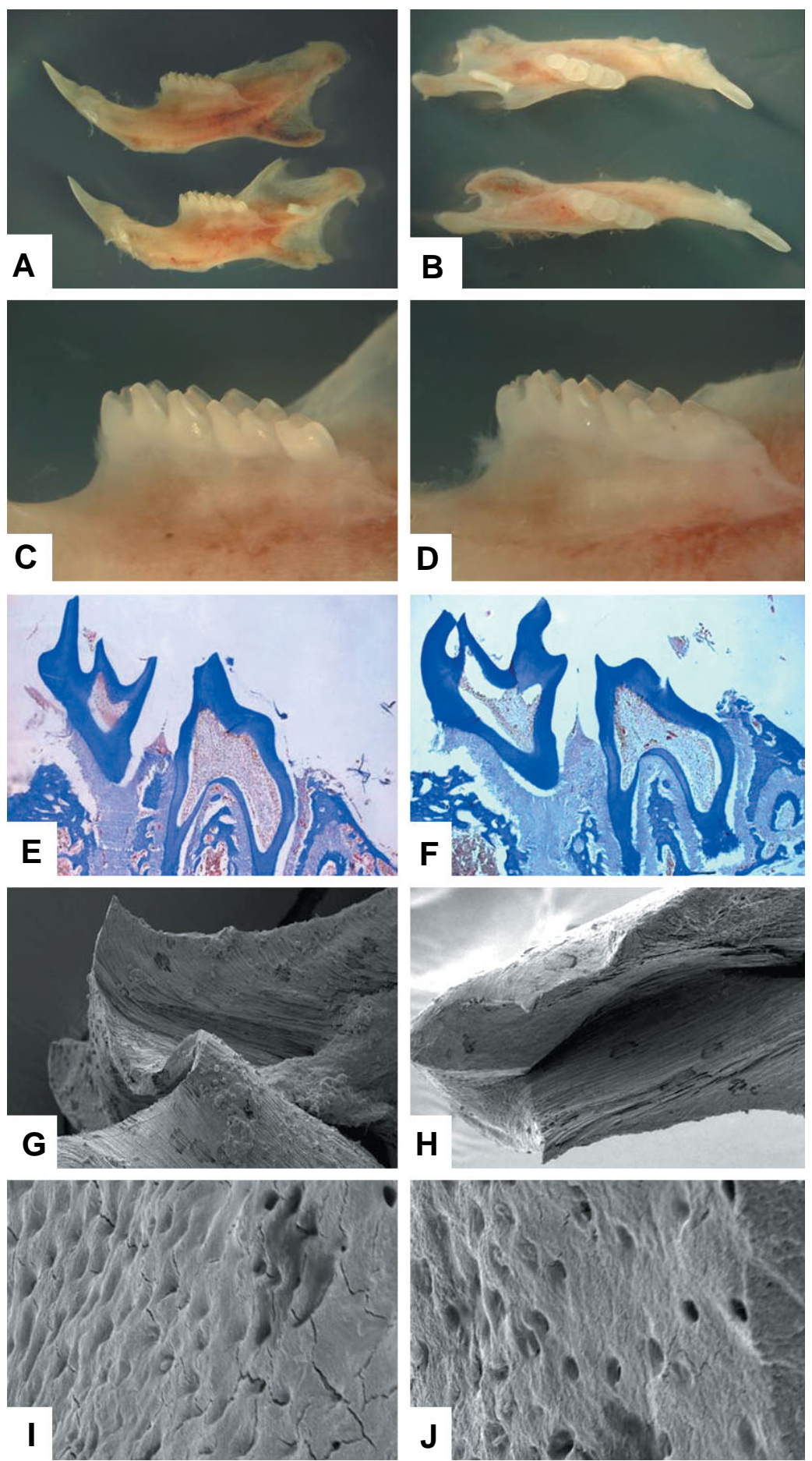

Fig. 4. Analyses of adult tooth phenotype of the caspase-3 knock-out homozygote and heterozygote mice on the B57BL/6 background. Comparison of the tooth pattern in the lower jaws of the homozygote (upper) and heterozygote (lower), side view (A), from above (B). Detailed view of the molar teeth in the lower jaw of the homozygote (C) and heterozygote (D). Microscopic images of molar tooth morphology of the homozygote mutant (E) and the heterozygote (F). Scanning electron microscopy of the first upper molar, adult caspase-3 knock-out mice on the B57BL/6 background. Low power SEM images of enamel rods, homozygote (G), heterozygote (H). High power SEM images of ground surface of enamel showing arrangement of ameloblasts, (I) homozygote, (J) heterozygote. 
frontal sections the brain can be seen to lie in between the unfused nasal processes directly on top of the tongue. This physical barrier appears to cause the face to flatten outwards, resulting in a much shorter upper jaw in the mutant compared to the wildtype. All midline facial structures, such as the palate, form (as indicated by the development of rugae) but are misshaped.

Our results suggest, that caspase- 3 is involved in dental apoptosis, but does not seem to be essential for molar tooth formation. Thus alterations caused by caspase- 3 deficiency at early stages of tooth development, particularly in the primary enamel knot area, do not affect final adult tooth pattern, morphology and differentiation.

\section{Materials and Methods}

\section{Animals}

Caspase-3 mutant mice on 129X1/SvJ and on a mixed background were obtained from the Department of Neuropathology, University of Alabama at Birmingham, USA (Prof. K.A. Roth) and generated as described in Leonard et al. (2002).

Caspase-3 mutant mice on B57BL/6 were provided by Dr. S. Lakhani (Howard Hughes Medical Institute, Yale University School of Medicine, New Haven, USA) and generated as described in Zheng et al. (2000).

\section{Samples}

Head parts of mutant and wild type mouse embryos E 15.5 were embedded in paraffin and sectioned frontally and sagittally using sections of $4 \mu \mathrm{m}$, split over three sections and mounted on SuperFrost Plus slides.

Adult jaws were skinned, decalcified ( $0.5 \%$ EDTA), paraffin embedded and sectioned saggitally using sections of $7 \mu \mathrm{m}$, split over two sections and mounted on SuperFrost Plus slides.

\section{Histology}

Morphology of tooth germs was evaluated after staining by haematoxylin-eosin in the embryonic tissue and by haematoxylin-eosin and trichrome staining in the adult tissue.

\section{TUNEL assay}

Terminal deoxynucleotidyl transferase-mediated dUTP nick end labelling ( / $n$ situ Cell Death Detection Kit) was used to detect apoptotic DNA breaks in individual cells. The procedure was carried out as described in the producer's directions (Roche Biochemicals) with pretreatment in $0.1 \%$ TRITONX-100 in 0.1 sodium citrate ( 8 mins, room temperature) and conversion using alkaline - phosphatase and NBT/NCIB color substrate. Aqueous eosin was used for counterstaining of the sections.

\section{PCNA (proliferating cell nuclear antigen)}

A polyclonal PCNA antibody (Santa Cruz) was exploited to detect proliferating areas in the sections. Primary antibody was applied for 1 hour (room temperature) after pretreatment in citric buffer (microwave irradiation for 10 mins). Application of the secondary antibody (labelled with horse radish peroxidase - HRP) for 30 mins was followed by colour reaction using $3,3^{\prime}$-diaminobensidine (DAB) as the substrate.

\section{In situ hybridisation}

Radioactive ${ }^{35} \mathrm{~S}$ in situ hybridisation was performed as described previously by Tucker et al. (1999). Mouse Fgf4 was linearized with Xmnl and transcribed with SP6. Mouse Shh was linearized with EcoR1 and transcribed with $\mathrm{T} 7$.

\section{Scanning electron microscopy}

After fixation in paraformaldehyde, samples were cracked open to the enamel structure and air dried for one week before coated for SEM. SEM was performed by the Centre for Ultrastructural Imaging at King's College London.

\section{Acknowledgements}

Supported by the Grant Agency of the Academy of Sciences, Czech Republic (KJB 500450503). Research in Brno lab runs in the frame of IRP IAPGNo. AVOZ50450515 and COSTB23. International cooperation was supported by the European Molecular Biology Organization (ASTF 195.0005), generation of caspase-3 knock-out by NIH (NS41962).

\section{References}

ARAKI, T., HAYASHI, M., NAKANISHI, K., MORISHIMA, N. and SARUTA, T. (2003). Caspase-9 takes part in programmed cell death in developing mouse kidney. Nephron Exp. Nephrology 93: 117-124.

BRONCKERS, A.L.J.J., GOEI, S.W., DUMONT, E., LYARUU, D.M., WÖLTGENS, J.H.M., VAN HEERDE, W.L., REUTELINGSPERGER, C.P.M. and VAN DEN EIJNDE, S.M. (2000). In situ detection of apoptosis in dental and periodontal tissues of the adult mouse using annexin-V-biotin. Histochem. Cell Biol. 113: 293-301.

COIN, R., KIEFER, S., LESOT, H., VONESH, J.L. and RUCH, J.V. (2000): Inhibition of apoptosis in the primary enamel knot does not affect specific tooth crown morphogenesis in the mouse. Int. J. Dev. Biol. 44: 389-396.

EIJNDE, S.M., LIPS, J., BOSHART, L., VERMEIJ-KEERS, C., MARANI, E., REUTELINGSPERGER, C.P.M. and ZEEUW, C.I. (1999). Spatiotemporal distribution of dying neurons during early mouse development. Eur. J. Neurosci. 11: $712-724$.

EARNSHAW, W.C., MARTINS, L.M. and KAUFMANN, S.H. (1999). Mammalian caspases: structure, activation, substrates and functions during apoptosis. Annual Rev. Biochem. 68: 383-424.

GULYAEVA, N.V. (2003). Non-apoptotic functions of caspase-3 in nervous tissue. Biochemistry (Mosc.) 68: 1171-1180.

HAKEM, R., HAKEM, A., DUNCAN, G.S., HENDERSON, J.T., WOO, M., SOENGAS, M.S., ELIA, A., DE LA POMPA, J.L., KAGI, D., KHOO, W., POTTER, J., YOSHIDA, R., KAUFMAN, S.A., LOWE, S.W., PENNINGER, J.M. and MAK, T.W. (1998). Differential requirement for caspase 9 in apoptosis pathways in vivo. Cel/94: 339-352.

JERNVALL, J., ÅBERG, T., KETTUNEN, P., KERÄNEN, S. and THESLEFF, I. (1998). The life history of an embryonic signalling center: BMP-4 induces p-21 and is associated with apoptosis in the mouse tooth enamel knot. Development 125: $161-169$.

KRAJEWSKA, M., WANG, H.G., KTAJEWSKI, S., ZAPATA, J.M., SHABAIK, A., GASCOYNE, R. and REED, J.C. (1997). Immunohistochemical analysis of in vivo patterns of expression of CPP32 (Caspase 3), a cell death protease. Cancer Res. 57: 1605-1613.

KUIDA, K., HAYDAR, T.F., KUAN, C.Y., GU, Y., TAYA, C., KARASUYAMA, H., SU, M.S., RAKIC, P. and FLAVELL, R.A. (1998). Reduced apoptosis and cytochrome c-mediated caspase activation in mice lacking caspase 9. Cel/ 94: 325337.

KUIDA, K., ZHENG, T.S., NA, S., KUAN, C., YANG, D., KARASUYAMA, H., RAKIC, P. and FLAVELL, R.A. (1996). Decreased apoptosis in the brain and premature lethality in CPP32-deficient mice. Nature 384: 368-372.

KUMAR, S. (2004). Migrate, differentiate, proliferate, or die: pleiotropic function of an apical "apoptotic caspase". SCi. STKE254: 49.

LEONARD, J.R., KLOCKE, B.J., D'SA, C., FLAVELL, R.A. and ROTH, K.A. (2002). Strain-dependent neurodevelopmental abnormalities in caspase-3-deficient mice. J. Neuropathol. Exp. Neurol. 61: 673-677.

LESOT, H., VONESH, J.L., PETERKA, M., TURECKOVÁ, J., PETERKOVÁ, R. and $\mathrm{RUCH}$, J.V. (1996). Mouse molar morphogenesis revised by three-dimensional reconstruction. II. Spatial distribution of mitoses and apoptosis in cap to bell stages first and second upper molar teeth. Int. J. Dev. Biol. 40: 1017-1031.

MATALOVA, E., ANTONARAKIS, G.S., SHARPE, P.T. and TUCKER, A.S. (2005a). Cell lineage of primary and secondary enamel knots. Dev. Dyn. 233: 754-759 MATALOVA, E., KOVARU, F. and MISEK, I. (2005b). Caspase 3 activation in the 
primary enamel knot of developing molar tooth. Physiol. Res. (Epub ahead of print).

MATALOVA, E., TUCKER, A.S. and SHARPE, P.T. (2004). Death in the life of a tooth. J. Dental Res. 83: 11-16.

NICHOLSON, D.W. and THORNBERRY, N.A. (1997). Caspases: Killer proteases. Trend Biochem. Sci. 22: 299-306.

RAFF, M.C., BARRES, B.A., BURNE, J.F., COLES, H.F., ISHIZAKI, Y. and JACOBSON, M.D. (1993). Programmed cell death and the control of cell survival: Lessons from the nervous system. Science 262: 695-700.

RANGER, A.M., MALYNN, B.A. and KORSMEYER, S.J. (2001). Mouse model of cell death. Nature Genetics 28: 113-118.

RESENDES, A.R., MAJO, N., SEGALES, J., ESPADAMALA, J., MATEU, E., CHIANINI, R., NOFRARIAS, M. and DOMINGO, M. (2004). Apoptosis in normal lyphoid organs from healthy normal, conventional pigs at different ages detected by TUNEL and cleaved caspase- 3 immunohistochemistry in paraffinembedded tissues. Vet. Immuno. Immunopathol. 99: 203-213.

RYOO, H.D., GORENC, T. and STELLER, H. (2004). Apoptotic cells can induce compensatory cell proliferation through the JNK and the Wingless signaling pathways. Dev. Cel/7: 491-501.

SCHWERK, C. and SCHULZE-OSTHOFF, K. (2003). Non-apoptotic functions of caspases in cellular proliferation and differentiation. Biochem. Pharmacol. 66: 1453-1458.

SHI, Y. (2002). Mechanisms of caspase inhibition and activation during apoptosis. Mol. Cel/9: 459-470.

SHIGEMURA, N., KIYOSHIMA, T., SAKAI, H., MATSUO, K., MOMOI, T., YAMAZA, H., KOBAYASHI, I., WADA, H., AKAMINE, A. and SAKAI H. (2001). Localization of activated caspase - 3 - positive and apoptotic cells in the developing tooth germ of the mouse lower first molar. Histochem. J. 33: 253-258.

TUCKER, A.S., AL KHAMIS, A., FERGUSON, C.A., BACH, I., ROSENFELD, M.G. and SHARPE, P.T. (1999). Conserved regulation of mesenchymal gene expression by Fgf-8 in face and limb development. Development 126: 221-228.

URASE, K., FUJITA, E., MIHO, Y., KOUROKI, Y., MUKASA, T., YAGI, Y., MOMOI, M.Y. and MOMOI, T. (1998). Detection of activated caspase 3 (CPP32) in the vertebrate nervous system during development by a cleavage site - directed antiserum. Dev. Brain Res. 111:77-87.

URASE, K., KOUROKU, Y., FUJITA, E. and MOMOI, T. (2003). Region of caspase3 activation and programmed cell death in the early development of the mouse forebrain. Brain Res. Dev. 145: 241-8.
VAAHTOKARI, A., ÅBERG, T. and THESLEFF, I. (1996). Apoptosis in developing tooth: association with an embryonic signalling center and suppression of EGF and FGF-4. Development 122: 121-129.

VARFOLOMEEV, E.E., SCHUCHMANN, M., LURIA, V., CHIANNILKULCHAI, N., BECKMANN, J.S., METT, I.L., REBRIKOV, D., BRODIANSKI, V.M., KEMPER, O.C., KOLLET, O., LAPIDOT, T., SOFFER, D., SOBE, T., AVRAHAM, K.B., GONCHAROV, T., HOLTMANN, H., LONAI, P. and WALLACH, D. (1998). Targeted disruption of the mouse Caspase 8 gene ablates cell death induction by the TNF receptors, Fas/Apo1 and DR3 and is lethal prenatally. Immunity 9:267-76.

VERHOVEN, B., KRAHLING, S., SCHLEGEL, R.A. and WILLIAMSON, P. (1999). Regulation of phosphatidylserineexposure and phagocytosis of apoptotic $T$ lymphocytes. Cel/ Death Dif. 6: 262-270.

WANG, J. and LENARDO, M.J. (2000). Roles of caspases in apoptosis, development and cytokine maturation revealed by homozygous gene deficiencies $J$. Cell Sci. 113: 753-757.

WOO, M., HAKEM, R., SOENGAS, M.S., DUNCAN, G.S., SHAHINIAN, A., KAGI, D., HAKEM, A., MCCURRACH, M., KHOO, W., KAUFMAN, S.A., SENALDI, G., HOWARD, T., LOWE, S.W. and MAK, T.W. (1998). Essential contribution of caspase-3/CPP32 to apoptosis and its associated nuclear changes. Genes Dev. 12: 806-819.

ZAKERI, Z., LOCKSHIN, R.A., CRIADO-RODRIGUEZ, L.M. and MARTINE,Z A.C. (2005). A generalized caspase inhibitor disrupts early mammalian development. Int. J. Dev. Biol. 49: 43-47.

ZHENG, T.S. and FLAVELL, R.A. (2000). Divinations and surprises: genetic analysis of caspase function in mice. Exp. Cell Res. 256:67-73.

ZHENG, T.S., HUNOT, S., KUIDA, K. and FLAVELL, R.A. (1999). Caspase knockouts: matters of life and death. Cell Death Differ. 6: 1043-1053.

ZHENG, T.S., SCHLOSSER, S.F., DAO, T., HINGORANI, R., CRISPE, I.N., BOVER, J.L. and FLAVELL, R.A. (1998). Caspase-3 controls both cytoplasmic and nuclear events associated with Fas-mediated apoptosis in vivo. Proc. Nat/. Acad. Sci. 95:13618-23.

Received: October 2005

Reviewed by Referees: February 2006

Modified by Authors and Accepted for Publication: February 2006

Published Online: March 2006 